\title{
15-18. Yüzyıl Arası Yabancı Dil Olarak Japonca Öğretiminde Kullanılan Ders Kitapları Üzerine Bir Değerlendirme:
} Çin ve Korelilerin Japonca Ders Kitapları

\author{
Ayşegül Atay \\ Doğu Dilleri ve Edebiyatları Bölümü, Edebiyat Fakültesi, Erciyes Üniversitesi, Kayseri, Türkiye
}

Sorumlu Yazar: Ayşegül Atay, aseyhan@erciyes.edu.tr

Makale Türü: Derleme Makalesi

Kaynak Gösterimi: Atay, A. (2021). 15-18. yüzyıl arası yabancı dil olarak Japonca öğretiminde kullanılan ders kitapları üzerine bir değerlendirme: Çin ve Korelilerin Japonca ders kitapları. Eğitimde Kuram ve Uygulama, 17(Özel Sayı 1), 47-59. doi: 10.17244/eku.878413

Etik Not: Araştırma ve yayın etiğine uyulmuştur. Bu çalışma, "Derleme Makalesi” olup ayrıca bir etik onay süreci işletilmemiştir.

An Evaluation of Textbooks Used in Teaching Japanese as a Foreign Language between the 15th-18th Centuries: Japanese Textbooks of Chinese and Koreans

\author{
Ayşegül Atay \\ Department of Eastern Languages and Literature, Faculty of Literature, Erciyes University, Kayseri, Turkey
}

Corresponding Author: Ayşegül Atay, aseyhan@erciyes.edu.tr

Article Type: Review Article

To Cite This Article: Atay, A. (2021). 15-18. yüzyıl arası yabancı dil olarak Japonca öğretiminde kullanılan ders kitapları üzerine bir değerlendirme: Çin ve Korelilerin Japonca ders kitapları. Eğitimde Kuram ve Uygulama, 17(Special Issue 1), 47-59. doi: 10.17244/eku.878413

Ethical Note: Research and publication ethics were followed. This study is "Review Article"; hence, no proceed an ethical clearance evaluation. 


\title{
15-18. Yüzyıl Arası Yabancı Dil Olarak Japonca Öğretiminde Kullanılan Ders Kitapları Üzerine Bir Değerlendirme: Çin ve Korelilerin Japonca Ders Kitapları
}

\author{
Ayşegül Atay \\ Doğu Dilleri ve Edebiyatları Bölümü, Edebiyat Fakültesi, Erciyes Üniversitesi, Kayseri, Türkiye
}

ORCID: https://orcid.org/0000-0002-8819-4959

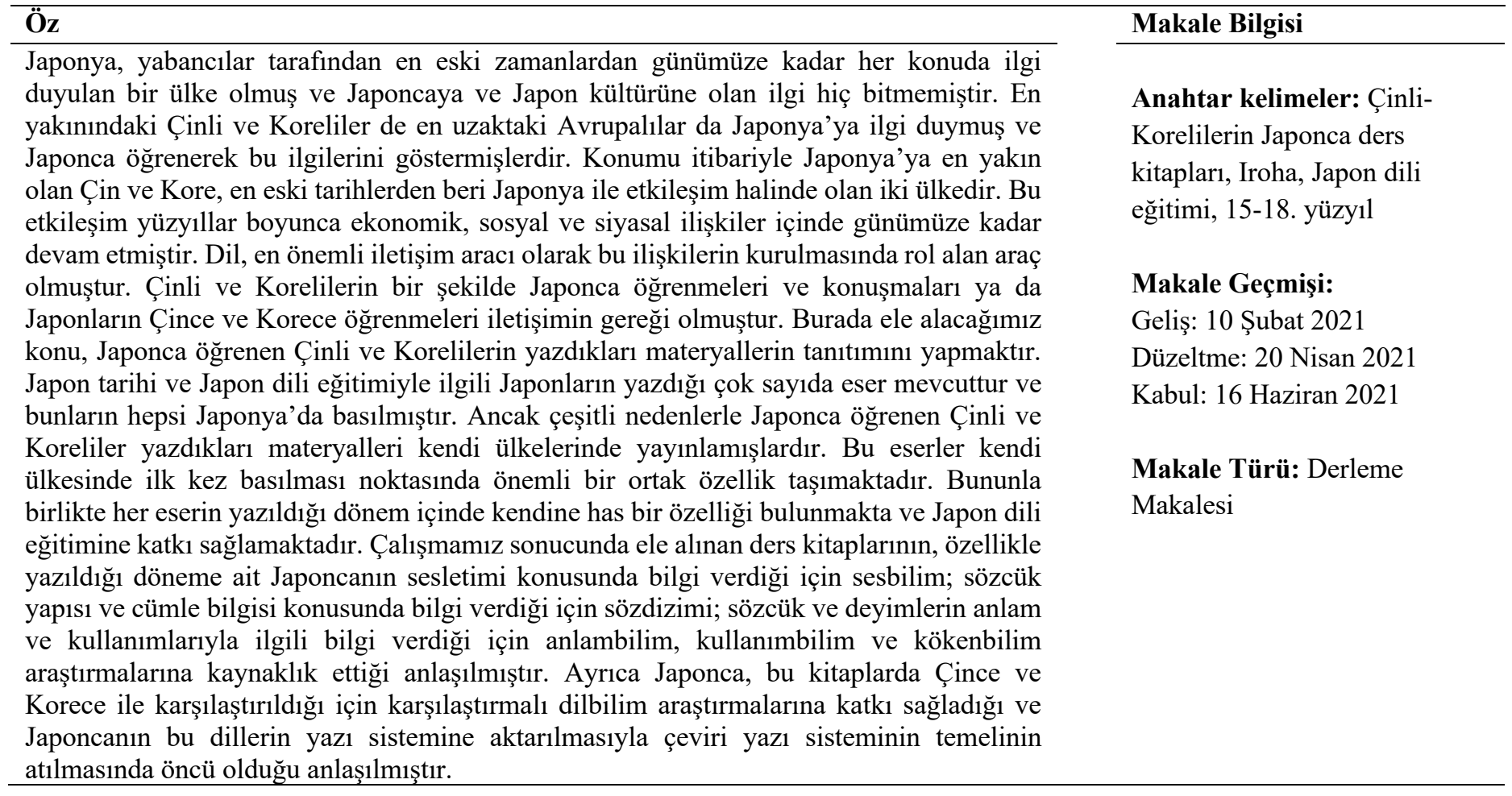




\section{An Evaluation of Textbooks Used in Teaching Japanese as a Foreign Language between the 15th-18th Centuries: Japanese Textbooks of Chinese and Koreans}

\begin{abstract}
Japan has been a country of interest by foreigners from the ancient times to the present day, and interest in Japanese and Japanese culture has never ceased. Both Chinese and Koreans, who are near and Europeans who are far were interested in Japan and showed this interest by learning Japanese. China and Korea, which are closest to Japan in terms of their location, are the two countries that have interacted with Japan since the ancient times. This interaction has continued for centuries in economic, social and political relations. Language, as the most important communication tool, has been the tool that plays a role in the establishment of these relationships. It has been a necessity of communication for Chinese and Koreans to learn and speak Japanese in some way or for Japanese to learn Chinese and Korean. The subject we will discuss here is to introduce the materials written by Chinese and Koreans learning Japanese. There are many works written by the Japanese on Japanese history and teaching Japanese language, all of which have been published in Japan. However, Chinese and Koreans learning Japanese published the materials they wrote in their own countries for various reasons. These works have an important common feature in terms of being published for the first time in their own country. However, each work has a unique feature in the period in which it was written and contributes to Japanese language education. As a result of our study, it is understood that it is a source for semantics, usage studies and etiology studies since it gives information about the meaning and usage of words and phrases -phonology as it gives information about the pronunciation of the textbooks, especially of the period in which it was written, in Japanese; syntax as it gives information about word structure and sentence information. In addition, since Japanese was compared with Chinese and Korean in those books, it has been understood that they contribute to comparative linguistics research and that Japanese is a pioneer in laying the foundation of the translative writing system by transferring these languages to the writing system.
\end{abstract}

Article Info

Keywords: Chinese -Korean's Japanese textbooks, Iroha, Japanese language education, 15 th-18th centuries

\section{Article History:}

Received: 10 February 2021

Revised: 20 April 2021

Accepted: 16 June 2021

Article Type: Review Article 


\section{Extended Summary}

Japan has been a country of interest by foreigners from the ancient times to the present day, and interest in Japanese and Japanese culture has never ceased. Both Chinese and Koreans, who are near and Europeans who are far were interested in Japan and showed this interest by learning Japanese. China and Korea, which are closest to Japan in terms of their location, are the two countries that have interacted with Japan since the ancient times. This interaction has lasted for centuries in economic, social and political relations. Language, as the most important communication tool, has been the tool that plays a role in the establishment of these relationships. It has been a necessity of communication for Chinese and Koreans to learn and speak Japanese in some way or for Japanese to learn Chinese and Korean. Our aim here is to compile and promote the works written by Chinese and Koreans learning Japanese. There are many works written by the Japanese on Japanese history and teaching Japanese language, all of which were published in Japan. However, Chinese and Koreans learning Japanese published the works they wrote in their own countries. These works have an important common feature in terms of being published for the first time in their own country. However, each work has a unique feature in the period in which it was written and contributes to Japanese language education.

In this study, literature review and compilation method were used. This topic, which has attracted great interest from the world, has drawn interest in Turkey as well. Although there are few published works on this subject in our country compared to other countries, there is actually a lot of interest in Japan and Japanese language education as a foreign language. The only problem is that since the works are in Japanese, those who do not speak Japanese cannot benefit directly from them. Therefore, in our study, firstly, Japanese articles and books written in the field of "Japanese Language Education History" in the literature were scanned. However, since the subject of Japanese language education is a very wide field, the subject of the study is limited to the materials written by Chinese and Koreans who learn Japanese and excluded the next research topic of the materials written by Europeans. In this study, all materials were used for the purpose of learning and teaching Japanese, which describe Japanese language, its grammatical features, meaning, usage and reading of words, and regional language differences, are included in the scope of the study and compiled under the title of "textbooks". On the other hand, non-subject books such as history, literature and medicine were excluded. Among the scanned works are articles related to the textbooks written by foreigners, as well as electronic resources and research books related to the textbooks. The materials mentioned in the aforementioned sources were compiled and the features of these books were highlighted in terms of their contribution to Japanese language education.

In the study, firstly, general information about Japan's internal administration and its relations with China and Korea were given under the title of "Japanese History between the 15th and 18th centuries". Then, Chinese and Korean Japanese Learning Initiatives were emphasized. The main subject of the study was discussed separately under the titles "Korean and Japanese Studies" and "Chinese and Japanese Studies". In each section, the physical and content features of the authors and their books were introduced. Under the title of "Evaluation", each book was shown in a table with its author, place of publication and features (in terms of contribution to Japanese language education) in chronological order and their importance is emphasized. 


\section{Giriş}

Japonya, yabancılar tarafindan en eski zamanlardan günümüze kadar her konuda ilgi duyulan bir ülke olmuş ve Japoncaya ve Japon kültürüne olan ilgi hiç bitmemiştir. En yakınındaki Çinli ve Koreliler de en uzaktaki Avrupalılar da Japonya'ya olan ilgilerini Japonca öğrenerek göstermişlerdir. Konumu itibariyle Japonya’ya en yakın olan Çin ve Kore, en eski tarihlerden beri Japonya ile etkileşim halinde olan iki ülkedir. Bu etkileşim yüzyıllar boyunca ekonomik, sosyal ve siyasal ilişkiler içinde günümüze kadar sürmüştür. Dil, en önemli iletişim aracı olarak bu ilişkilerin kurulmasında rol alan araç olmuştur. Çinli ve Korelilerin bir şekilde Japonca öğrenmeleri ve konuşmaları ya da Japonların Çince ve Korece öğrenmeleri iletişimin gereği olmuştur. Burada amacımız, Japonca öğrenen Çinli ve Korelilerin yazdıkları eserlerin derleyerek tanıtımını yapmaktır. Japon tarihi ve Japon dili eğitimiyle ilgili Japonların yazdığı çok sayıda eser mevcuttur ve bunların hepsi Japonya'da basılmıştır. Ancak Japonca öğrenen Çinli ve Koreliler yazdıkları eserleri kendi ülkelerinde yayınlamışlarıdır. Bu eserler kendi ülkesinde ilk kez basılması noktasında önemli bir ortak özellik taşımaktadırlar. Bununla birlikte her eserin yazıldığı dönem içinde kendine has bir özelliği bulunmakta ve Japon dili eğitimine katkı sağlamaktadır.

Bu çalışmada alanyazın taraması ve derleme yöntemi kullanılmıştır. Japonya'da ve dünyada çok ilgi gören bu konuya Türkiye'de de büyük ilgi duyulmaktadır. Diğer ülkelere kıyasla ülkemizde bu konuda yayınlanmış eser her ne kadar az olsa da aslında Japonya'ya ve yabancı dil olarak Japon Dili eğitimine ilgi oldukça fazladır. Tek sorun eserler Japonca olduğu için bu eserlerden Japonca bilmeyenlerin doğrudan yararlanamamasıdır. Bu nedenle çalışmamızda öncelikle alanyazındaki "Japon Dili Eğitim Tarihi” alanında yazılmış Japonca makaleler ve kitaplar taranmıştır. Ancak, Japon dili eğitim tarihi konusu oldukça geniş bir alan olduğundan çalışmanın konusu, Japonca öğrenen Çinli ve Korelilerin yazdıkları malzemelerle sınırlandırılmış olup Avrupalıların yazdıkları bir sonraki araştırma konusu olarak kapsam dışı bırakılmıştır. Bu çalışmada, Japoncanın tanıtımını yapan, onun nasıl bir dil olduğunu, dilbilgisel özelliklerini, sözcüklerin anlam, kullanım ve okunuşları ile yöresel dil farklılıklarını anlatan Japoncayı öğrenme ve öğretme amacıyla kullanılmış bütün malzemeler inceleme kapsamına alınarak "ders kitapları" başlı̆̆1 altında derlenmiştir. Buna karşın, tarih, edebiyat ve tıp gibi konumuzun haricindeki kitaplar kapsam dışında bırakılmıştır. Taranan eserler arasında yabancıların yazdığı ders kitapları ile ilgili makaleler bulunduğu gibi, ders kitaplarıyla ilgili elektronik kaynaklar ve araştırma kitapları da mevcuttur. Söz konusu kaynaklarda adı geçen malzemeler derlenerek, Japon dili eğitimine katkısı açısından bu kitapların özellikleri ön plana çıkarılmıştır.

Çalışmada öncelikle "15 - 18. yüzyıllar arası Japon Tarihi” başlığı altında Japonya'nın hem iç yönetimi hem de Çin ve Kore ile olan ilişkileri konusunda genel bilgi verilmiştir. Ardından Çinli ve Korelilerin Japonca öğrenme girişimleri üzerinde durulmuştur. Çalışmanın ana konusu, "Koreliler ve Japonca Çalışmaları" ile "Çinliler ve Japonca Çalışmaları" başlıkları altında ayrı ayrı ele alınmıştır. Her bir bölümde yazarlar ve kitaplarının fiziki ve içerik özellikleri tanıtılmıştır. "Değerlendirme" başlığı altında her kitap kronolojik ${ }^{1}$ sıraya göre yazarı, basım yeri ve özellikleri (Japon dili eğitimine katkısı açısından) ile tablo içinde gösterilerek bunların önemi vurgulanmıştır.

Bu çalışma, Türkiye'de Japon dili eğitimine ilgi duyan araştırmacılar için başvuru kaynağı olmasının yanı sıra, okuyucuların alana özgü genel bilgi edinmeleri ve onlarda merak uyandırması bakımından önemlidir. Ayrıca, 15-18. yüzyılları arasında yazılmış bu kitapların tanıtımının Türkçe olarak yapılmış olması bir ilktir.

Çalışma, kayıtlarda geçen ilk ders kitabından (15. yüzyıl) Edo Dönemi (18. yüzyıl) sonuna kadarki süre ile sınırlandırılmıştır. Japon tarihiyle ilgili eserlere bakıldığında bu süre oldukça karmaşık bir dönemdir. Tarihi açıdan 1518. yüzyıllar arasındaki bu dört yüzyıl boyunca Japonya, içeride $s h \overline{o g u n l a r}{ }^{2}$ ve samuraylar $^{3}$ arasında mücadelenin ve iç savaşların sürdüğü, dışarıda ise Asya anakarasında bulunan devletlerle olan üstünlük mücadelesinin sürdüğü derebeylikler ülkesidir. Bu zaman aralığı, Japonya'da yaşananların çok karmaşık olduğu ve Japonya'nın düzenli bir devlet olma özelliği taşımadığı bir süreçtir. Bu karmaşık ve uzun tarih içinde Japon dili eğitimi açısından yaşanan en olumlu olayın, yabancıların Japonca öğrenme isteği sonucunda ortaya çıkardıkları eserler olduğu düşüncesindeyiz.

Son yıllarda Japon dili eğitimi tarihiyle ilgili Japonya'da yapılmış pek çok araştırma bulunmaktadır. Bu araştırmaların özellikle ilgi çekici noktası bütün dergilerin "Japon Dili Eğitim Tarihi” başlığıyla özel sayı olarak basılmış olduğudur. Bu eserlere ulaşmak ve onları okumak Japon dili eğitimine ilgi duyan ve Japonca bilmeyenler için oldukça zor ve karmaşık bir süreçtir. Japon dili eğitim tarihiyle ilgili ülkemizde az sayıda eser bulunmakla birlikte özellikle kullanılan birincil kaynağın Japonca olması açısından bu çalışmaların her biri çok değerli olup alana katkıları büyüktür. Türkçe olan bu eserlerden söz etmek gerekirse, "Japon Dili Eğitim Tarihi” (İrim \& Özbek, 2018) adlı derleme kitabı, "Japonya'nın İkinci Dünya Savaşı öncesi ve sırasında yabancılara yönelik uygulanan Japon dili eğitimi politikalarını" ortaya koymaktadır. Ayrıca, kitapta Tayvan'da gerçekleştirilen Japon Dili eğitimi

\footnotetext{
${ }^{1}$ Kronolojik sıralamada Japon Dili Eğitim Ansiklopedisinde (Nihongo Kyouiku Gakkaihen, 2005) (日本語教育辞典Nihongo Kyouiku Jiten) tarihi olayların yer aldığı kronolojik sıra temel alınmıştır.

${ }^{2}$ Shōgun (将軍): Çince kökenli bir sözcüktür. Kelime anlamı, orduyu kumanda eden asker. Japonya'da askeri rütbe ve tarihsel bir ünvandır.

${ }^{3}$ Samuray (サムライ): Derebeylerin yönetimi altındaki askerler.
} 
uygulamalarını anlamak amacıyla o dönemi deneyimlemiş kişilerle yapılan görüşme ve incelemeler de bulunmaktadır. Bu kitap, derleme ve inceleme kitabı olması açısından alanında Türkçe yazılmış ilk ve önemli bir kitap olma özelliği taşımaktadır. İkinci sıradaki "Modern Japon Eğitim Sisteminin Tarihi Temelleri Üzerine Değerlendirme: Meiji'den Shōwa'ya 1868-1950 Arası Döneme Bakış” (Özşen, 2020) adlı makaledir. Bu makalede Özşen (2020), “19. yüzyıl son çeyreğinden İkinci Dünya Savaşı sonrasındaki sürece odaklanarak, Japon eğitim sisteminin tarihsel zeminini dönemin sosyal, kültürel, siyasal ve jeopolitik dinamikleri çerçevesinde ve Japonya'nın sosyokültürel kodları üzerine" incelemede bulunmaktadır. Son olarak alanyazında iki eser daha yer almaktadır. Bunlardan birincisi cumhuriyetin ilanından sonra Türk Japon Cemiyeti tarafından 1936 yılında Tokyo'da basılan “Japonca-Türkçe, Türkçe-Japonca Lügat" başlıklı iki dilli sözlükle ilgili Gençer'in (2017) tanıtım yazısıdır. Diğeri ise, "II. Abdülhamit Dönemine Ait İki Farklı Japon Alfabesi ve Türkçe Transliterasyonlarındaki Sorunlar Üzerine" başlıklı Baloğlu Gençer'in (2020) araştırma makalesidir. Baloğlu Gençer (2020), makalesinde Dündar'ın (2018) tanıtımına kadar Osmanlı'da ilk Japonca yayın olarak bilinen ancak Noda ve öğrencileriyle ilgili olmayan Japon Elifbası (1908) ile Mecmua-1 Lügat'te (1893) yer alan Hiragana alfabesini karşılaş̧ırmıştır. Nitel araştırmaya dayalı karşılaştırmasının sonucunda "on beş yıl arayla yazılmış bu alfabelerin Türkçe transliterasyonlarında kayda değer farklardan" söz etmektedir. ${ }^{4}$

\section{5 - 19. Yüzyıllar Arası Japon Tarihi}

15-19. yüzy1llar arası Japonya'da sirasıyla Muromachi (Ashikaga) (1336-1573), Azuchi Momoyama (1568-1603) ve Edo (Tokugawa) (1603-1868) dönemleri hüküm sürmüștür (Masahide \& Kadowaki, 1995).

Tokugawa Ieyasu, imparator tarafindan 1603 yılında shogun olarak görevlendirilmiştir. Ieyasu'nun yönetime el koymasıyla shogunluklar arasındaki kargaşa son bulmuş ve 1603 yılında Edo Dönemi başlamıştır (Küçükyalçın, 2013:189). Ieyasu, fethettiği toprakları destekçilerine dağıttı ve Edo'da kendi Tokugawa Shogunluğunu kurdu. Bu dönemde Japonya Tokugawa Shogunluğu ile 300 yerel derebeyi yönetimine girdi (Yurdusev, 2013:5-22). Başkent Kyoto'dan Edo'ya (bugünkü Tokyo) taşındı. Bu dönem Japonya'nın en modern olduğu dönemdir (Esenbel, 2012). Edo Dönemi boyunca Portekizliler ateşli silahlarıyla, büyük gemileri ve askeri kabiliyetleriyle Japon savaşçı-soylu sınıfını etkilerken, diğer yandan Hristiyan misyonerler de halkı etkilemeye çalışmışlardır (Huffman \& Çev: Yücel, 2020:71). $\mathrm{Bu}$ durumdan rahatsız olan shogunluk, Hristiyan misyonerlik faaliyetlerini yasaklamış, Hollandalılar dışındaki tüm yabancılara ticareti kapatmıştır. ${ }^{5}$ Böylece ülkeye giriş-çıkışların büyük ölçüde yasaklanmış olduğu dönem olan $E d o$ Dönemi Japonya'nın tecrit (kapalılık) dönemi olarak bilinmektedir (Yurdusev, 2013:12). Bu kapalıl1k döneminde hiç savaş olmadığ i için Japon tarihinin kendi içinde en barışçıl dönemi olduğu da söylenmektedir. Edo Dönemi 1868'de son bulmuş ve ardından Meiji Dönemi başlamıştır. Meiji Dönemi her alanda köklü değişikliklerin yapıldığı, Japonya'nın dünyaya kapılarının açıldığı dönemdir.

Yukarıda anlatıldığı gibi Japonya' da iç politika ve ülkenin genel durumu karışık idi. Bu dönemlerde Japonya'nın Kore ve Çin'le ilişkileri nasıldı?

15. yüzyıl başları Japonların Çin ve Kore ile olan ilişkilerinin zayıfladığg dolayısıyla Japon korsanların aktif olduğu bir süreçtir (Saeki, 2014). 1443 yılında Japonya ve Kore arasındaki "Üç Liman Antlaşması" (Changwo, Busan ve Yōm-po adlı üç liman) gereğince Japonya 100 gemiye kadar Kore yarımadasında bulunan limanlarda ticaret yapabilecek ve bu limanlarda ikamet edebilecekti. Bu nedenle, 15. yüzyılın başlarından itibaren özellikle Tsushima ${ }^{6}$ Adası kökenli Japonlar, bu limanlara gelerek yaşamaya (sayıları 3000 civarında) başladılar. Ancak aralarından kaçakçılık ve yasadışı balıkçılıkla uğraşanlar ortaya çıkınca, bir de aynı kişiler, Korelilere yönelik saldırılarda bulununca o zamanki Kore-Chungjong Krallı̆̆ (1506-44) bu üç limanı kapsayacak şekilde ağır siyasi reformlar getirdi ve kontrolü ele aldı. Kore hükümetinin baskıcı önlemlerine karşı, üç limanda yaşayan Japonlar 1510 yılında bir araya gelerek ayaklandılar. Ayaklanma Üç Liman İsyanı ${ }^{7}$ olarak adlandırılmaktadır. Bu ayaklanma sonucunda Kore ve Japonya arasındaki diplomatik ve ticari ilişkiler tamamen bozuldu. Daha sonraki yıllar, birbirlerine karşı üstünlük mücadelesi kurmak için gelişen olaylar zinciri içinde geçti (Saeki, 2014).

15. yüzyıl başlarında Japonya'nın Çin ile olan ilişkileri de Kore ile yaşadığı ilişkilerden farksızdır (Saeki, 2014). Yine 15. yüzyılda Çin ve Japonya arasında tıpkı Kore ve Japonya arasında gerçekleşen Üç Liman İsyanı'na benzer olaylar meydana geldi. Bu olaylardan birincisi, Ningbo ${ }^{8}$ kargaşası, ikincisi ise taksitli ticaretin çöküşüdür. Ningbo kargaşası, Ming Hanedanlı̆̆ı'na (Çin'e) karşı Japonların ayaklanmasıdır. Ayaklanmanın asıl nedeni haraç meselesidir ve taksitli ticaretin lideri olma mücadelesi için Ningbo ticaret limanında olay patlak verir. Bu olayla birlikte Çin ve Japonya arasında anlaşmazlıklar başladığı için deniz ticareti durma noktasına gelmiştir.

\footnotetext{
${ }^{4}$ Yapıtlarla ilgili, bakınız: Gençer-Baloğlu (2020)

${ }^{5}$ Ticaretin sadece Hollandalılara açık bırakılması konusunda ayrıntılı bilgi için Erkin (2001)'in "Edo döneminde Hollandalıların Shogunluğa sundukları yıllık raporlar” adlı doktora tezine bakılabilir.

${ }^{6}$ Güney Kore ile Japonya arasında bir Japon adasıdır.

${ }^{7}$ Riod of the Three Ports.

${ }^{8}$ Çin sahillerinde bulunan önemli limanlardan birisidir.
} 
Yukarıdaki olayların etkisini gösterdiği 16. yüzyıl boyunca Japonya, Kore ve Çin arasındaki diplomatik ilişkiler hiç iyi olmamıştır. Bu olayların nedenleri arasında, Tsushima'nın Japonya ve Kore arasındaki ticareti tekeline alması, Japonya-Çin arasındaki çatışmalar yüzünden ilişkilerin kesilmesi ve Japon korsanların yasadışı faaliyetlerini daha da artırması sayılabilir (Saeki, 2014). Ayrıca Japonlar, 1593 yılında Kore'yi işgal edince, Kore'yi savunmak ve Japon saldırısını püskürtmek amacıyla Çin, Kore'ye destek verir. Böylece iki ülke Japonya'ya karşı birleşmiş olur. ${ }^{9}$

17. yüzyılda Japon tüccarlar ve Çinli deniz tüccarları arasındaki mal dolaşımının hızla artışına Avrupalıların gelişi de eklenebilir. Ayrıca Edo Dönemi'nde (17. yüzyıl) Japonya ile Avrupa arasında ilk bağlantı Çin gemisiyle Tanegashima Limanına giriş yapan tüccarlar vasıtasıyla olmuştur (Dündar, 2006). Yukarıda anlatılan olaylarda olduğu gibi Doğu Asya'dan Güney Doğu Asya'ya uzanan denizcilik dünyası, karmaşık bir şekil almasıyla birlikte son derece yakın ekonomik ilişkiler çağına girdiği görülmektedir.

Japonya'nın 17. yüzyıldan itibaren Edo Dönemi'nde dünyaya kapanması ya da tecrit olarak adlandırılan sürece girmesiyle, Hollandalılar dışındaki yabancılarla ilişkiler yasaklanmıştı. Bundan sonraki başlıkta bu boyunca Çinli ve Korelilerin Japonca öğrenme girişimleri ve bunun sonucunda ortaya çıkardıkları ders kitapları kronolojik sırayla ele alınacaktır.

\section{Çinli ve Korelilerin Japonca Öğrenme Girişimleri}

Uzak Doğu Asya ülkesi olan Japonya, tarih boyunca yabancıların ilgi duyduğu bir ülke olmuştur. Yakın komşuları Kore ve Çin'le devamlı savaş halinde olmaları, ülkeler arasındaki zorunlu göçler ve ticari nedenlerle her zaman bu ülkeler, birbirlerinin dilini- kültürünü öğrenmek için girişimlerde bulunmuşlardır. Bu girişimler, Japonca öğrenen Koreli ve Çinlilerin öğrendiklerini kendi dilleriyle açılamaya çalışma girişimleridir. Bunun tam tersi Japonlar için de söylenebilir.

Bundan sonraki bölüm, Koreli ve Çinlilerin yazdıkları kitapları kronolojik sırayla ve yazar isimleriyle tanıtarak her kitabın Japon dili eğitimine katkısı açısından özelliklerini belirttiğimiz bölümdür.

\section{Koreliler ve Ders Kitapları}

Kore ve Japonya'nın birbirine coğrafi olarak yakın olmaları, iki ülkenin erken dönemlerde çeşitli nedenlerle ilişki kurmalarına yol açtı. Bunun doğal sonucu olarak da Japonca öğretmeye yönelik bilinen ilk yapıt Koreliler tarafından yazılmıştır. Takamizawa (2004) makalesinde 1492 yılında Kore'de yayınlanan ve ilk Japonca ders kitabı olan "i-ro-ha" (伊呂波) ile ilgili içerik bilgisi vermektedir. Japonca abece denilen “i-ro-ha”(伊呂波), Japon yazısını ve Japonca dilbilgisini Hangıl ${ }^{10}$ yazı sistemi açıklayan en eski ders kitabıdır. Adını o zamanlar Japon yazı sisteminin ilk 3 hecesi olan i-ro-ha $a^{11}$ seslerinden almaktadır. Bu seslerin Kanji olarak yazılışı sırasıly i-ro-ha (伊呂波) sesleridir. $\dot{I}$-ro-ha başlıklı kitapta Japonca kana ${ }^{12}$ alfabesinin her bir sesinin karşısına Korecesi Hangll ile yazılıdır. "İ-ro-ha" şekil olarak yukarıdan aşağıya- soldan sağa doğru Kana yazı sisteminin ve onun solunda Hangıl yazılı olan eserdir (Görsel 1). I-roha, Japoncanın yazı karakterini, sözcükleri ve cümleleri açıklayıcı özelliğe sahip olduğu için Kore Çeviri Enstitüsü’nün Japonca çeviri derslerinde ders kitabı olarak kullanılmıştır. Ayrıca kitap Koreceden günümüz Japoncasına çevrildiğinde o dönemin Japonca telaffuzunun esas alındığı anlaşılmaktadır. Örneğin; Japonca chi ve tsu'nun sürtünmeli ses olmadığ 1 gibi (Takamizawa,2004).

İ-ro-ha'dan sonra ikinci sırada yer alan kitap, Gang Woo Seang adında bir Korelinin yazdığı "Shōkai Shingo" (捷解新語) adındaki “Açıklamalı Yeni Dil” kitabıdır. Gang Woo Seong, esir olarak götürüldüğü Japonya'da 10 y1l bulunmuş, bu 10 y1l boyunca çok iyi Japonca öğrenmiş ve ülkesine döndükten sonra bilgilerini kitap haline getirmiş, ancak kitabı ölümünden 40 yıl sonra yayımlanmıştır (Takeda, 2012). Hayatının sonuna kadar Kore'deki Çeviri Enstitüsünde tercümanlık yaparak iki ülke arasında diplomatik çalışmalara katkıda bulunmuştur. Açılamalı Yeni Dil adlı kitap, 10 cilttir. $\mathrm{Bu} 10$ ciltlik kitabın içeriği, genel olarak hem konaklama yerinde kalan müşterilerin kendi aralarındaki konuşmalar hem de konak yeri sahibiyle olan konuşmalardan oluşmaktadır. Buna göre 1,2,3,4 ve 9. ciltte Koreli ve Japon yetkililer arasında geçen görüşmeler; sonraki dört ciltte $(5,6,7,8$. ciltler) Koreli iyi niyet elçilerinin Japonya'yı ziyaretiyle ilgili konuşmalar ve son cilt olan 10. ciltte ise o dönemde yazılmış mektuplar yer almaktadır. İç sayfasında ise yukarıdan aşağıya- sağdan sola doğru ve her sayfada 4'lü sıra halinde Japonca kana yazı sistemi, bunun sağında Korece okunuşu, solunda ise Çince (Kanji) okunuşu yer almaktadır (Görsel 2). Ayrıca kitabın iki sayfasının açıldığı tam ortasında kitabın adı ve cilt sayısı yazılıdır. Bu yapıt, 1678 yılından itibaren Japonca öğretiminde kullanılan tek kitap olmuştur (Takeda, 2012). ev sahibi (王ō) ve misafir (客kyaku) arasında geçen konuşmalara yer verilmektedir.

\footnotetext{
${ }^{9}$ Japon korsanları (1550-1570) Çin sahil kentlerinden Hangzhou ve Ningbo'ya saldırarak geniş çaplı yıkıma neden oldukları için, Kore ile müttefik olma ihtiyacı duymuştur. https://www.chinasage.info/japan.htm E.T.12.12.2020.

${ }^{10}$ Kore alfabesi.

${ }^{11}$ Japon alfabesini açıkladığı için Japonca abece'si olarak da adlandırılır.

12 Japon yazısı sistemine verilen ad.
} 


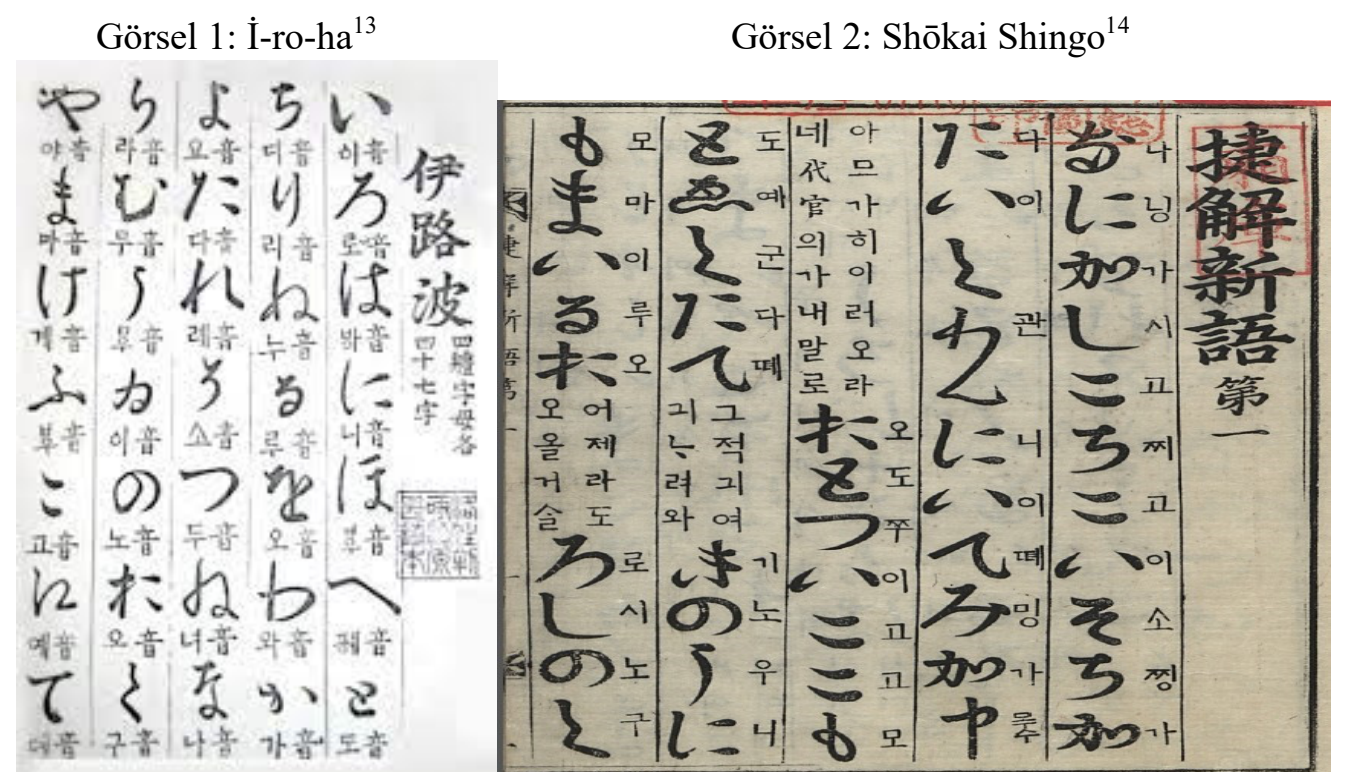

Üçüncü sırada yer alan kitap, Koreli Hong Maimei tarafından yazılmış “Wagoruikai” (倭語類解) ${ }^{15}$ adında Japonca eşanlamlılar sözlüğüdür (Görsel 3 ve 4). 1780’li yıllarda yayınlanmıştır. Bu sözlükte astronomi, hava durumu, zaman birimi, coğrafya, dil, kelimeler ve resmi kurum adlarıyla birlikte yaklaşı 3400 kelime bulunmaktadır. Ayrıca Japonca kelimelerin anlam ve okunuşları Hangll ile yazılıdır. Ayrıca kitapta, Gugyeol ${ }^{16}$ sistemi kullanılarak Japonca edatlar, "shassharei" ve "itashimashitaniyori" gibi deyimsel ifadelere açıklamalı olarak yer verildiği için, günümüz Japonca Korece fonetik araştırmalara ve kökenbilimi araştırmalarına ışık tutmaktadır (Takamizawa, 2004). Bu sözlük, Kore'de tercüman yetiştirme programlarında kullanılmış, daha sonra da Japonya'da yaşayan Korelilere Japonca öğretmek amaciyla Japonya’ya getirilmiştir (Kim, Son-u, \& Chon, 2016).

Görsel 3: Wagoruikai’yin Dış Kapağı Görsel 4: Wagoruikai'yin İlk Sayfas1

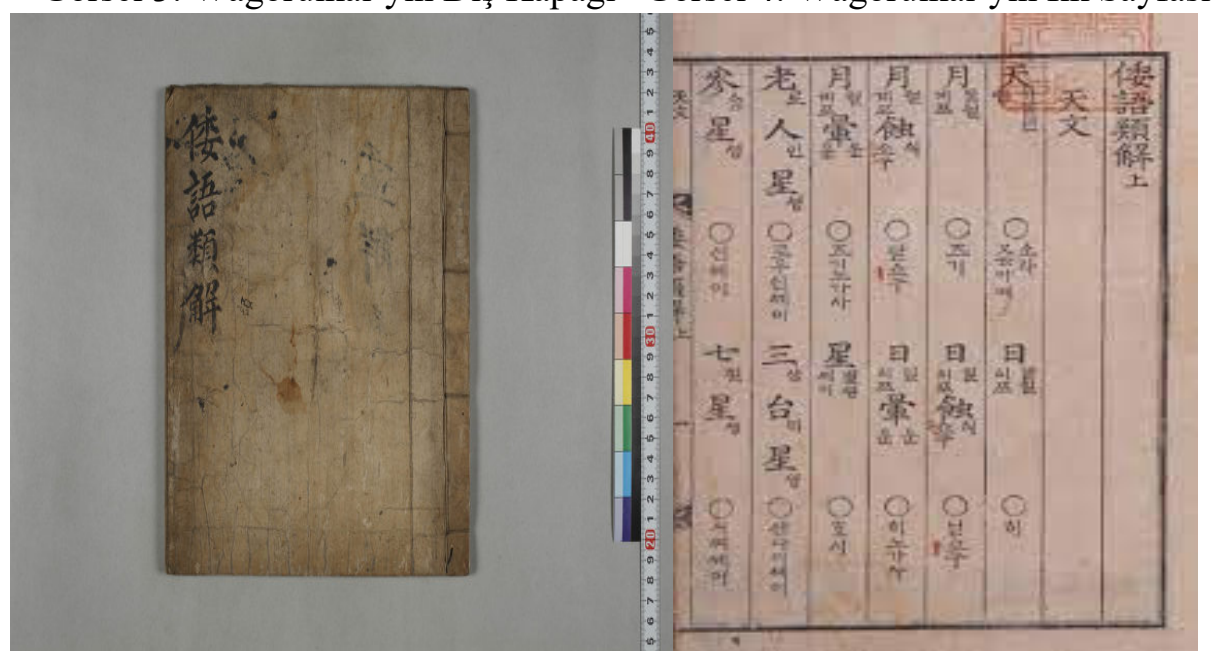

Dördüncü sıradaki ise, yazarı belli olmayan “Ringo Taihō” (隣語大力) ${ }^{17}$ adlı kitaptır. 204 sayfadan oluşan kitabın birinci cildi 1710 yılında, 2. cildi ise 27 yıl aradan sonra 1737 yılında yazılmışıı (Fumitaka, 2010). Kitap

\footnotetext{
${ }^{13}$ Görsel 1: https://theqoo.net/square/1100542883; Erişim Tarihi: 20.01.2021

${ }^{14}$ Görsel 2: http://egloos.zum.com/gil092003/v/9681168; Erişim Tarihi: 23.01.20212

15 http://m.blog.daum.net/rotring/16454797; Erişim Tarihi: 10.10.2020

16 Klasik Çince ile yazılmış metinleri anlaşılır Korece'ye dönüştürmek için bir sistemdir. Ayrıntı için ilgili sayfaya bakılabilir. http://cefia.aks.ac.kr:84/index.php?title=Understanding_Korea_materials_-_Hangeul:_2._Transcription_of_Korean_Using_Chinese_Characters; Erișim Tarihi: 30.11 .2020

17 Görsel 3 ve 4: Elektronik kitap olarak Japon Edebiyatı ve Kültürü Araştırma Merkezinin resmî sitesinden alınmıştır. http://base1.nijl.ac.jp/iview/Frame.jsp?DB_ID=G0003917KTM\&C_CODE=0006-

024709\&IMG_SIZE=\&PROC_TYPE=null\&SHOMEI=\%E3\%80\%90\%E9\%9A\%A3\%E8\%AA $\% 9 \mathrm{E} \% \mathrm{E} 5 \% \mathrm{~A} 4 \% \mathrm{~A} 7 \% \mathrm{E} 6 \% 96 \% \mathrm{~B} 9 \% \mathrm{E} 3 \% 80 \% 91$ $\& R E Q U E S T \_M A R K=$ null\&OWNER=null\&BID=null\&IMG_NO=1 E.T.11.12.2020
} 
yukarıdan aşağı ve sağdan sola doğru olup, sayfadaki yazılardan sağdaki Japonca kana, bunun solundaki Korece Hangıl olarak yazılıdır. O yıllarda Kore Çeviri Enstitüsü'nde Japonca çalı̧̧ma kitabı, Japonya'da ise tercümanlar için Korece çalışma kitabı olarak kullanılmış olan bu kitabın 1790 yılında Choi Ki-Ryong ${ }^{18}$ tarafından derlendiği belirtilmektedir (National Hangeul Museum, 2014) ${ }^{19}$. Kore'nin güney doğu lehçesiyle ilgili bilgi vermektedir.
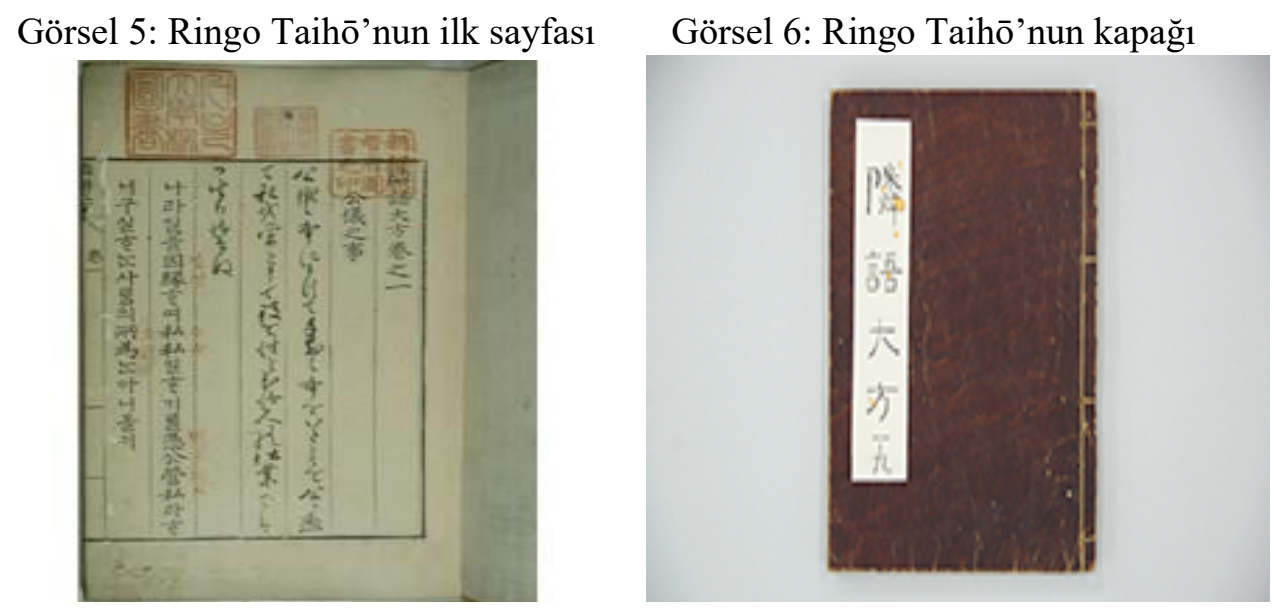

Yukarıda tanıtımlarını yaptığımız Koreliler tarafından yazılmış ve Kore'de basılmış olan bu dört ders kitabın ortak özellikleri, Japonca yazı sistemini Hangıl yazı sistemiyle açıklamış olmaları, hem günlük konuşmalar hem de diplomatik görüşmelere ait Japonca diyalogların sol tarafına karşılıklarının Hangll olarak yazılmış olmalarıdır. Açıklayıcı bir şekilde yazıldığı için, bu kitaplar o dönemin Japonca ve Korece'nin sesletimine, başka bir ifadeyle Korece-Japonca karşılaştırmalı çalı̧̧malara fonetik açıdan kaynak olmuşlar ve olmaya devam etmektedirler.

\section{Çinliler ve Japonca Ders Kitapları}

Koreliler Japoncayı öğrenmeye- öğretmeye yönelik çalışmalar yaparken, Çinliler de çok daha önceden Japonya hakkında araştırmalara başlamışlardır. Ancak ders kitabı niteliğinde eserlerini Korelilerden sonra yazdıkları görülmektedir. Birbirlerine yakın olmanın avantajı, dezavantajıyla tarih boyunca siyasi bakımdan ya üstünlük kurma mücadelesinde ya da kendilerini Japon işgaline karşı koruma çabasında bulunma gibi çeşitli nedenlerden dolayı Japonca öğrenmeye çalışmışlardır. Bunun sonucunda da aşağıda tanıtımını yapacağımız kitaplar ortaya çıkmıştır. ${ }^{20}$

Görsel 7: "Shoshi Kaiyō” Ansiklopedinin 8. cildinde yer alan iroha (いろは)

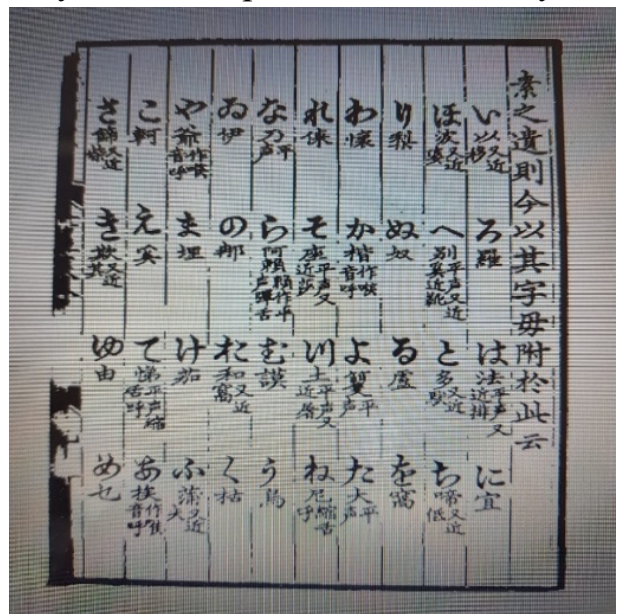

\footnotetext{
${ }^{18}$ Orijinal ismi崔麒齢 (チェ・ギリヨン) Okunuşu Cho-Girion

19 "Ringotaihō" ile "Tyōsengoyaku" Japonca ve Korece öğrenmek için yazılmış bu kitaplar arasında karşılaştırma yapmak üzere proje kapsamında yapılmış bir araştırmadır. Bu araştırmanın sonuç raporu kısa adı Kaken (bilimsel araştırmalar için oluşturulan veri tabanında) olan veri tabanında sunulmuş halidir.

${ }^{20}$ Çinlilerin yazdığı tarih kitaplarında mutlaka Japonlara özgü bilgiler yer almaktadır. Örneğin üçüncü yüzyıl Japonya’sı ile ilgili en fazla bilgiye “Üç Krallığın Hikayesi” adlı Çin tarih kitabında (三国志) rastlanır. Bu kitapta Japonya'nın şehir isimleri, resmi unvan ve özel isimler Çince karakterlerle yazılmıştır. Bunun gibi başka konularda yazılmış Çince kitaplar bulunmakla birlikte, bu kitaplar konumuzla ilgili olmadığı için kapsam dışı bırakılmıştır.
} 
1376 y1lında yayınlanan “Shoshi Kaiyō" (書史会要) adlı tarih kitabında “i-ro-ha” başlı̆ğ altında Japon yazıs1 (abece) yer almaktadır. Toplam 10 ciltten oluşan bu serinin 8. cildinde "Yabancılarla İlişkiler" başlığı altında Japon yazısı "i-ro-ha" 21 adıyla tanıtılmış ve her bir Japonca sesin karşısına Çince sesletimi yazılmıştır (Takamizawa,2004). Bu kısım, Japonca chi ve tsu (ツve チ), seslerinin Çince tu, ti (土) olduğu, ho (ホ) sesinin ise duruma göre Çince $\phi$ a ya da bo (波) olarak sesletilmesiyle ilgili örneklerde görüldüğ̈̈ gibi Japon yazısındaki tüm seslerin Çince telaffuzunu içermektedir. Bu kısım, Japonca chi ve tsu (ツve チ), seslerinin Çince tu, ti (土) olduğu, ho (ホ) sesinin ise duruma göre Çince фa ya da bo (波) olarak sesletilmesiyle ilgili örneklerde görüldüğü gibi Japon yazısındaki tüm seslerin Çince telaffuzunu içermektedir.

İkinci sırada yer alan “Nihongo kokukōryaku” (日本語国考略) adlı kitap, Shun Fuji adlı Çinli tarafindan derlenmiştir. Bu kitap Japonya hakkında bilgiler başta olmak üzere, sözcükler, astronomi, zaman dilimi, kıyafet türleri, yiyecek içecek vs. olmak üzere toplam 15 kategoriden oluşmaktadır (Takamizawa.2004). Kitabın bir bölümünde, “Nihonyogo" (日本寄語) başlı̆̆ altında Japonca sözcüklerin açıklamaları bulunduğundan bu bölüm sözlük niteliğindedir. Yazarın 363’ten fazla Japonca sözcüğü bir araya getirdiği bu sözlük 1523 yılında yayınlanmış olsa da günümüzde aslı mevcut değildir. Japonca sözcüklerin okunuşları Kanji (Çince) ile yazıldığ 1 için, dönemin sesletimiyle ilgili bilgi edinmede önemli bir kaynaktır. Ancak, kitapta anlaşılmayan yerlerin de olduğu belirtilmektedir (Seki, 2008).

Görsel 8: "Nihongo kokukōryaku"22

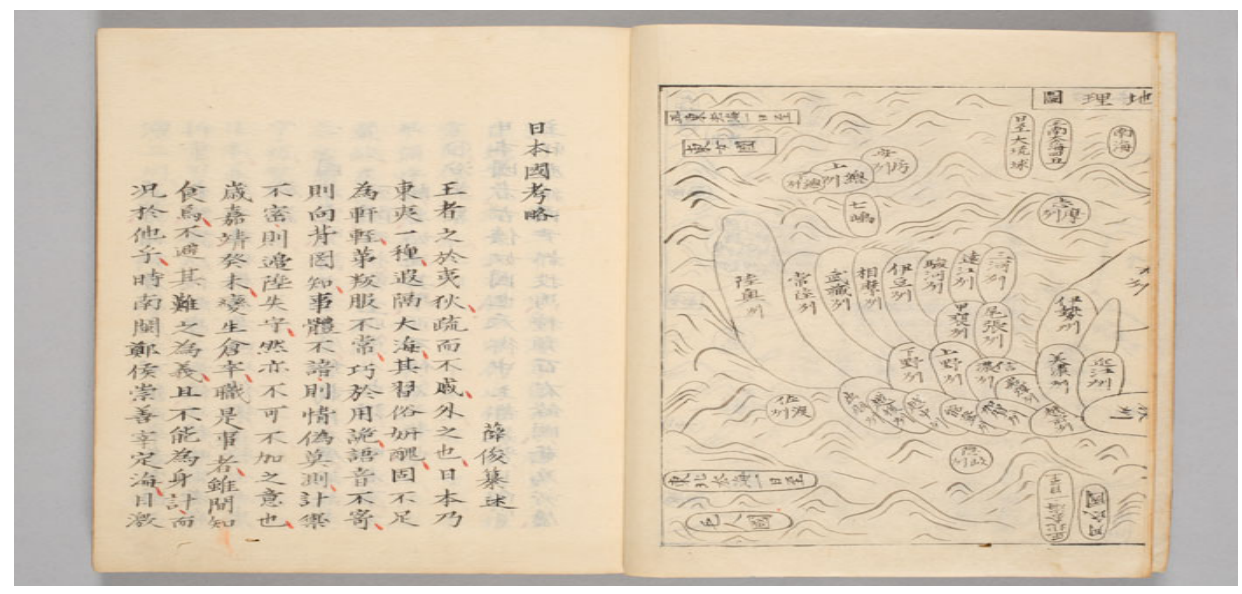

Üçüncü sırada tanıtacağımız kitap “Nihonkan Yakugo” (日本館訳語) adlı kitaptır. Ancak bu kitabın yazarı bilinmemektedir. Kitap, Çinli tercümanların çeviri dersinde kullanmak için derlenen ve 13 ciltten oluşan "Kaiyakugo" (華夷訳語) adlı Çince yabancı diller sözlüğünün bir cildini oluşturmaktadır. Bu sözlükte Japonca 566 sözcük ve deyimsel ifadeler bulunmaktadır. Japonca sözcüklerin okunuşu ve çevrisi Çincedir (Seki, 2008). Ayrıca, Japonya'da konaklama yerlerinde kalan diplomatlar arasında geçen günlük konuşmalar ile resmi görüşmeler de yer almaktadır.

Görsel 9: "Kaiyakugo"23 Çince Yabancı Diller Sözlüğünün giriş sayfası

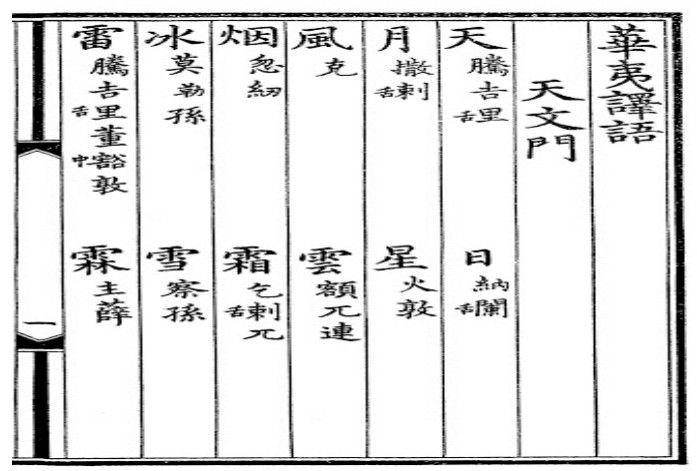

\footnotetext{
${ }^{21}$ Bu bölümle ilgili ayrıntılı açıklama için bakınız: https://www.jstage.jst.go.jp/article/gengo1939/1950/16/1950_16_1/_pdf

22 National Archives of Japan adlı sayfadan alınmıştır.

http://www.archives.go.jp/exhibition/popup_jousetsu_23_1/popup_jousetsu_23_3_0002.html

${ }^{23}$ Sözlüğün Japonca sözcükleriyle ilgili cilde ait görsel bulunamamıştır.
} 
Son olarak tanıtacağımız dördüncü kitap, Chung Mai Gong tarafından 1565 yılında derlenen "Nihon-ikkan” ( 本一鑑) adlı Japonya konulu kitaptır. Yazar, Japonya'da kaldığ 16 ay boyunca deneyimlerini yazarken Japonlarla olan görüşmelerinden de söz ederek kitabının içeriğini zenginleştirmiştir. Bu kitapta Japon tarihi, kültürü, geleneklerinin yanı sıra Japon dili ile ilgili bilgiler bulunmaktadır. 16 ciltten oluşan ansiklopedinin Japoncayla ilgili kısımda 3404 sözcük ve bunların Çince açıklamaları yer almaktadır (Seki, 2008).

Görsel 10: "Nihon-ikkan"24

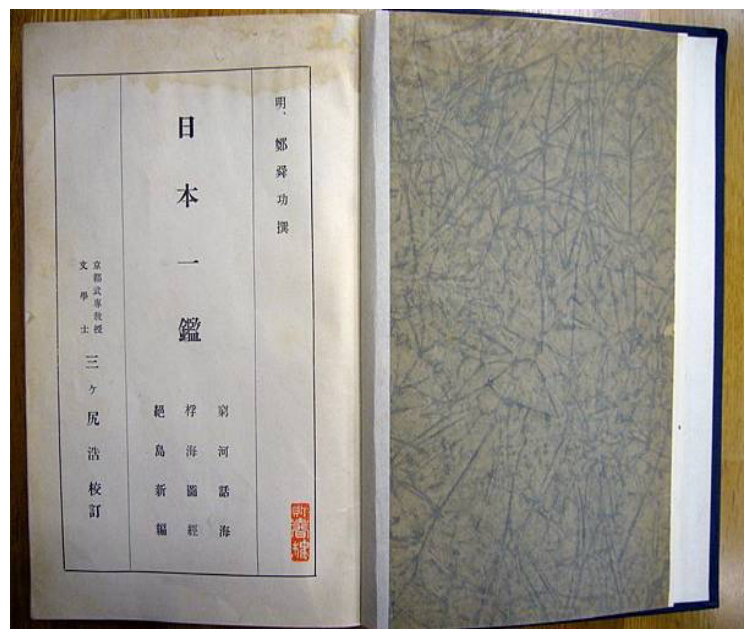

Yukarıda tanıtımını yaptığımız ders kitapları Çinli ve Korelilerin Japonca öğrenme-öğretme amacıyla yazdıkları kitaplar olup, yazıldığı dönemde kullanılan Japoncanın özelliklerini açıklayan en eski yapıtlardır.

\section{Değerlendirme}

Bu bölümde çalışma boyunca derlenen ve Japon Dili eğitimine katkısı olan Çinli ve Korelilere ait ders kitaplarının adları, yazarları ve özellikleri tablolarda özetlenmiş ve bunların değerlendirmeleri yapılmıştır.

Kore ve Çin'in Japonya'ya yakın olmaları birbiriyle siyasi, ekonomik ve toplumsal bağlamda ilişki kurmalarını hızlandırmış ve buna bağlı olarak birbirinin dilini, kültürünü anlamaya yönelik kitaplar yazıldığı görülmüştür. Yazı sistemleri Japon yazısından farklı olan Çinli ve Koreliler, Japoncayı kendi yazı sistemlerine çevirmeye çalışmışlardır. Hangll yazı sistemiyle yazılan ilk Japonca ders kitabı I-ro- $h a$, Japoncayı öğretmeye yönelik ilk adımdır. Ayrıca, Japonca karakterlerin Korece okunuşlarının olması, Japoncadan Korece'ye çevriyazı sisteminin ilk kez bu eserde yapıldığı ve bu kitabın daha sonra yabancılar tarafından yazılan kitaplar için ilk kaynak olduğu düşüncesini doğurmaktadır. Çinli ve Korelilerin yazdıkları diğer ders kitaplarının özellikleri ve Japon dili eğitimine katkıları aşağıdaki tabloda derlenmiştir.

Tablo 1. Koreli ve Çinlilerin Ders kitapları

\begin{tabular}{|c|c|c|c|}
\hline No & $\begin{array}{l}\text { Basım yılı } \\
\text { / Yeri }\end{array}$ & Kitabın Adı / Yazarı & $\begin{array}{l}\text { Japon Dili Eğitimine Katkısı Açısından } \\
\text { Kitabın Özellikleri }\end{array}$ \\
\hline 1 & 1492- Kore & $\begin{array}{l}\text { Iroha伊呂波/ } \\
\text { Yazarı bilinmiyor }\end{array}$ & $\begin{array}{l}\text { Yazılan ilk Japonca ders kitabıdır. Dönemin Japonca telaffuzuyla } \\
\text { ilgili Korece olarak verdiği bilgiler açısından kökenbilim ve } \\
\text { sesbilime katkısı vardır. }\end{array}$ \\
\hline 2 & 1523- Çin & $\begin{array}{l}\text { Nihonyogo日本寄語/ } \\
\text { Shun Fuji }\end{array}$ & $\begin{array}{l}\text { Japonca sesletim Kanji sesine dönüştürüldü. } \\
\text { Sesbilim ve çeviri yazıya katkısı olmuştur. }\end{array}$ \\
\hline 3 & 1549- Çin & $\begin{array}{l}\text { Nihonkan Yakugo日本館訳語- (Yazarı } \\
\text { bilinmiyor) }\end{array}$ & $\begin{array}{l}\text { Çeviri eğitiminde kullanılmak üzere yazılmış, Çince sesletimiyle } \\
\text { sözcük ve kalıplar bulunmaktadır. Sesbilim, anlambilim ve } \\
\text { kullanımbilim alanlarına katkısı vardır. }\end{array}$ \\
\hline
\end{tabular}
içermektedir. Ayrıca bunlarla ilgili sözcüklerin Çince karşılıkları yazılı olduğu için anlambilim, sesbilim ve kökenbilim araştırmalarına katkısı olmuştur.

\footnotetext{
${ }^{24}$ Blog sayfasından alınmıştır. https://nicecasio.pixnet.net/blog/post/397901779; Erişim Tarihi: 20.02.2021
} 
5

1676- Kore

6

$1780-$ Kore

$1790-$ Kore
倭語類解新語Wagoruikaishingo / Yazarı bilinmiyor

倭語類解 Wagoruikai /

Hong Maimei

隣語大方Ringo Taihō /
Korece- Japonca karşılaştırmalı araştırmalar için önemli bir dilbilim kaynağıdır.

Japonca eş anlamlılar sözlüğü, anlambilim,

fonetik ve kökenbilim araştırmalarına kaynaklık yapmaktadır.

Korecenin Japonca açılanmış şeklidir. Korece ve Japonca karşılaştırmalı dilbilime katkısı olmuştur.

Choi Ki-Ryong

\section{Sonuç}

Buna göre, genel olarak bu kitapların Japon dili ve eğitimine katkıları konusunda yapılan derlemede aşağıdaki sonuca varılmıştır.

- Yazıldığı döneme ait Japoncanın sesletimi konusunda bilgi verdiği için sesbilim,

- Sözcük yapısı ve cümle bilgisi konusunda bilgi verdiği için sözdizimi,

- Sözcük ve deyimlerin anlam ve kullanımlarıyla ilgili bilgi verdiği için anlambilim, kullanımbilim ve kökenbilim,

- Bu kitaplarda Japonca, Çince ve Korece ile karşılaştırıldığ 1 için karşılaştırmalı dilbilim,

- Japoncanın bu dillerin yazı sistemine aktarılmasıyla çeviri yazı sisteminin temellerinin atılmasına katkısı olduğu anlaşılmıştır.

Bu kitapların Çin ve Kore'de ortaya çıkarıldığg zaman aralığında, Avrupalılar da boş durmamıştır. Diğer bir ifadeyle, sadece Çinli ve Koreliler değil, Avrupalılar da Japonya'ya olan ilgilerini farklı yollarla göstermişler ve kendi dillerinde Japonca üzerine kitaplar yazmışlardır. Avrupalıların Japonya'ya neden gidip Japonca öğrendikleri ve özellikle misyonerlerin Japon dili eğitimi için neler yaptıkları konusu bundan sonraki araştırma konusunu oluşturmaktadır.

\section{Araștırmacıların Katkı Oranı}

Yazar çalışmanın tamamını gerçekleştirmiştir.

Yazar çalışma için herhangi bir finansal destek almamıştır.

\section{Destek ve Teșekkür}

Çıkar Çatış̧ması

Yazar çalışmada herhangi bir çıkar çatışmasının bulunmadığını beyan etmiştir. 


\section{Kaynakça / References}

Arisaka, H. (b.t.). Shoshikaihyou "Iroha" no onshu ni tsuite [Eserledeki Iroha'nın sesletimi hakkında]. Erişim: https://www.jstage.jst.go.jp/article/gengo1939/1950/16/1950_16_1/_pdf

Dündar, A. M. (2006). Panislamizmden'den Büyük Asyacılı̆̆a. İstanbul: Ötüken Neşriyat.

Egloos. (2021, 02 23). Erişim: http://egloos.zum.com/: http://egloos.zum.com/gil092003/v/9681168

Erkin, H. C. (2007). Edo döneminde Hollandalıların Shogunluğa sundukları yıllık raporlar (Yayımlanmamış doktora tezi). Ankara Üniversitesi, Ankara.

Esenbel, S. (2012). Japon Modernleşmesi ve Osmanlı - Japonya'nın Türk Dünyası ve İslam Politikaları. İstanbul: İletişim.

Fumitaka, K. (2010). A new study of Ringotaihou, comparing with Tyoosengoyaku stored in the Hattori Collection. Kaken. Erişim: https://kaken.nii.ac.jp/en/grant/KAKENHI-PROJECT-19320061/

Gencer, Z. (2017). İki dilli sözlükler ilk Japonca-Türkçe Türkçe-Japonca Sözlük. Sözmer Bülten (s. 8).

Gençer-Baloğlu, Z. (2020). II. Abdülhamit Dönemine ait iki farklı Japon Alfabesi ve Türkçe transliterasyonlarındaki sorunlar üzerine. Selçuk Üniversitesi Edebiyat Fakültesi Dergisi, (44), 275-294.

Huffman, J. L. (2020). Japonya Tarihi (Çev. C. Yücel). İstanbul: İnkılap Kitabevi.

Ikegami, M. (Çev.). (1993). Nihongo Shoubunten [Japon Dili üzerine]. Iwanami Shoten. Erişim: https://ci.nii.ac.jp/ncid/BN09397907

İrim, N. B., \& Özbek, A. (2018). İkinci Dünya Savaşı ve öncesi Japon Dili Eğitimi Tarihi. İstanbul: Paradigma.

Küçükyalçın, E. (2013). Dönüm Noktalarıyla Japon Tarihi - Samuraylar Çağı. İstanbul: İnkılap.

Kölürbaşı, N. S. (2017). Modern bir imparatorluğun anatomisi. İstanbul: Küsurat Yayınları.

Kuşculu, A. (2007). Japonya'da hristiyan misyoner hareketleri (1542-1587) (Ed. İ. Görener). Bilimname, 2(8), $139-151$.

Kyung, S. H. (1991). A comparison in the style of a manuscript with two printed books of "Wagoruikai": A reconstruction of the original of the "Naeshirogawa Manuscript". Touhoku Daigaku Bungakubu Nihongogakka Ronshuu, 1, 92-106.

Lee, D.-W. (2002). On the notation of the "Yotsu-Gana" that appear in Japanese learning books of the chosen period. Hiroshima Daigaku Daigakuin Kyouikugaku Kenkyuuka Kiyou, 2(51), 401-410.

Masahide, B., \& Kadowaki, T. (1995). Shin-nihonshi B [Yeni Japon Tarihi]. Tokyo: sūkenshuppan.

National Hangeul Museum. (2014). Hangul History (Part 2: Easy to learn and use). Erişim (27.12.2020): https://www.hangeul.go.kr/lang/jp/html/traceHangeul/traceHangeul238.do

National Institute of Korean Language. (b.t.). [특집] 국어사 자료로 만나는 선인들의 삼 왜학서로 만나는 선인들의 삼정승혜 수원여자대학교 비서과 교수 [Ataların yaşamlarl Kore tarihi materyalleri aracıliğıyla bir araya geldi]. Erişim: https://www.korean.go.kr/nkview/nklife/2014_1/24_0104.pdf

Nihongo Kyouiku Gakkaihen. (2005). Nihongo Kyouiku Jiten [Japon Dili Eğitimi Ansiklopedisi]. Nihongo Kyouiku Gakkaihen.

Özşen, T. (2020). Modern Japon Eğitim Sisteminin tarihi temelleri üzerine değerlendirme: Meiji'den Shōwa'ya 1868-1950 arası döneme bakış. Eğitimde Kuram ve Uygulama, 16(1), 36-52.

Ringo Daihou (隣語大力). (b.t.). Online Journal "Studies in Japanese Literature and Culture". Erişim: http://base1.nijl.ac.jp/iview/Frame.jsp?DB_ID=G0003917KTM\&C_CODE=0006-

024709\&IMG_SIZE=\&PROC_TYPE=null $\&$ SHOMEI=\%E3\%80\%90\%E9\%9A\%A3\%E8\%AA $\% 9 \mathrm{E} \% \mathrm{E} 5 \% \mathrm{~A} 4 \% \mathrm{~A} 7 \% \mathrm{E} 6 \%$ $96 \% \mathrm{~B} 9 \% \mathrm{E} 3 \% \overline{8} 0 \% 91 \& \mathrm{REQUEST}$ _MARK $=$ null\&OWNER=null $\& \mathrm{BID}=$ null $\& I M G \_N O=1$ 
Atay

Saeki, K. (2014). Japanese-Korean and Japanese-Chinese relations in the Sixteenth Century. In J. B. Lewis, The East Asian Wars, 1592-1598: International Relations, Violence and Memory (p. 402). London: Routledge.

Seki, M. (2008). Nihongo Kyouikushi Kenkyuu Josetsu [Japonca eğitimi]. 3anet.

Shudan Houjin Nihongo Kyouiku Gakkai . (2005). Encyckopedia of Japanese Language Education. Tokyo: Taishukan.

Takamizawa, H. (2004). Nihongo Kyouikushi (1) Gaikokujin to Nihongo [Japon dili eğitim tarihi - Yabancılar ve Japonca]. Gakuen, 1-7. Erişim: http://id.nii.ac.jp/1203/00003409/

Takamizawa, H. (2005b, 9). Nihongo Kyouikushi (3), Edo Jidai no Gaikokujin Nihongo Gakushuusha [Edo dönemi yabanc1 uyruklu Japonca öğrenenler]. Gakuen, 2-9. Erişim: https://ci.nii.ac.jp/naid/40006925340

Thegoo. (b.t.). Thegoo.net. Erişim: https://theqoo.net/square/1100542883

Understanding Korea Materials. (b.t.). CEFIA. Erişim: http://cefia.aks.ac.kr:84/index.php?title=Understanding_Korea_materials_-

Yurdusev, A. N. (2013). Japonya'nın Avrupa uluslararası toplumuna entegrasyonu. A. M. Tunçoku içinde, Japon dış politikasıSistematik ve bölgesel aktörlerle ilişkiler (ss. 5-22). Ankara: Nobel.

Zheng, G., Pe , S., \& Jin Yu, Z. (2016). Wagoruikai Kenkyuu [Japonca eşanlamlı sözcükler araştırması]. (online) Rinkawa Shoten Book Depository. 